
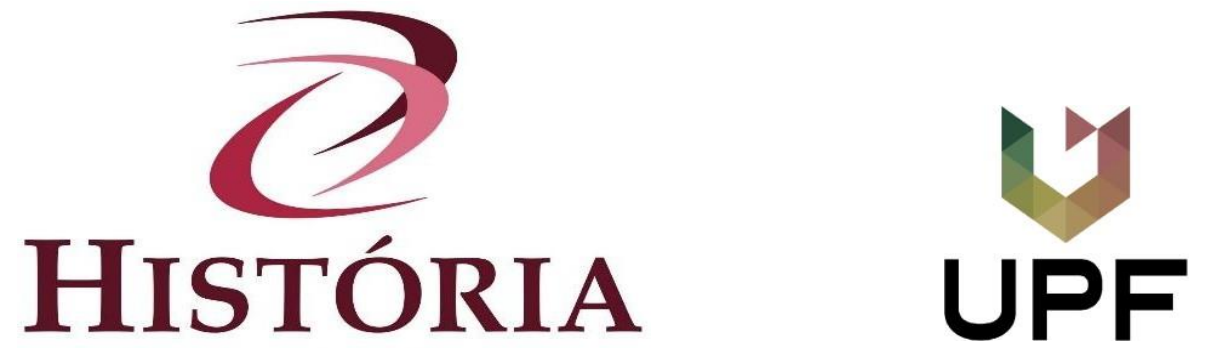

debates e tendências

Colonizar ou não colonizar, eis a questão.

Portugal e suas possessões africanas no século XIX.

\author{
To colonize or not to colonize, that is the question. \\ Portugal and its African possessions in the nineteenth century.
}

\author{
Colonizar o no colonizar, esa es la cuestión. Portugal y sus posesiones \\ africanas en el siglo XIX.
}

Rodrigo do Prado Bittencourt ${ }^{\mathrm{i}}$

\begin{abstract}
Resumo
O estudo do empreendimento colonial português em África não pode prescindir de uma análise das alternativas que Portugal tinha (além de colonizar com mais efetividade suas possessões ultramarinas). Não se pode analisar a História a partir do ponto de vista do presente, mas é preciso avaliar as vantagens e desvantagens de tal empreendimento. Isto deve ser feito mediante a análise das vantagens e desvantagens das outras opções que o país tinha: vender suas possessões; investir mais em regiões negligenciadas de seu próprio território; estabelecer uma colonização mais branda e, por conseguinte, mais barata e menos militarista ou ainda, por fim, retomar o modelo colonial utilizado na América, com forte participação da Igreja Católica.

Palavras-Chave: África. Colonialismo. Portugal.
\end{abstract}

\begin{abstract}
The study of the Portuguese colonial enterprise in Africa cannot do without an analysis of the alternatives that Portugal had (instead of promoting a more effective colonization of their overseas possessions). History cannot be analyzed from the point of view of the present, but it is necessary to evaluate the advantages and disadvantages of such an undertaking. This must be done by analyzing the advantages and disadvantages of the other options that the country had: selling its possessions; investing more in neglected regions of your own territory; to establish a softer and, therefore, cheaper and less militaristic colonization or, finally, to resume the colonial model used in America, with a strong participation of the Catholic Church.
\end{abstract}

Keywords: Africa. Colonialism. Portugal. 


\title{
Resumen
}

El estudio de la empresa colonial portuguesa en África no puede prescindir de un análisis de las alternativas que tenía Portugal (además de colonizar más eficazmente sus posesiones de ultramar). La Historia no se puede analizar desde el punto de vista del presente, pero es necesario evaluar las ventajas y desventajas de tal empresa. Esto debe hacerse analizando las ventajas y desventajas de las otras opciones que tenía el país: vender sus posesiones; invertir más en regiones desatendidas de su propio territorio; establecer una colonización más suave y, por tanto, más barata y menos militarista o, finalmente, retomar el modelo colonial utilizado en América, con una fuerte participación de la Iglesia Católica.

Palabras Clave: África. Colonialismo. Portugal.

Deve-se analisar cuidadosamente a relação entre Portugal e suas Colônias Africanas. Relação que vai crescer em importância, com a crise econômica do final do século e a crise política do Ultimato Britânico. Sabe-se que, embora antigas, as colônias portuguesas em África não foram tão exploradas quanto o Brasil e mesmo após a independência deste país, o comércio com a ex-colônia americana continua a ser mais intenso que aquele estabelecido com as possessões portuguesas no continente africano.

\begin{abstract}
Apesar da quebra profunda que a desagregação do Império provocara no comércio externo português, é de notar que, durante quase todo o século XIX, o Brasil continuou a importar produtos agrícolas, nomeadamente o vinho e alguns alimentos. Por sua vez, fornecia parte do algodão, açúcar e couros, para além de outras matérias-primas tropicais que a indústria portuguesa utilizava. No entanto, os montantes das exportações manter-se-iam baixos até aos meados do século, altura em que se inicia uma recuperação moderada, até às décadas de 70 e 80. É só a partir daqui que o comércio com as colônias africana irá começar a superar o do Brasil (ALEXANDRE, 1993, p. 251).
\end{abstract}

Durante muito tempo, estas colônias africanas interessaram a Portugal mais como fornecedoras de "mercadoria humana" (seres humanos escravizados que são aprisionados aos milhares e vendidos para o Brasil) do que como mercados consumidores ou produtores de algum bem material. Com a pressão inglesa, o Brasil deixa de comprar escravos em 1850 e se é verdade que o tráfico não deixará de existir de imediato, apenas por respeito às leis, também é certo que ele irá diminuir a ponto de um dia desaparecer, na segunda metade do século XIX. Isto devido à interferência inglesa, mas também à depreciação do negro escravizado diante da imigração europeia, que fornecia mão-de-obra branca para as lavouras de café a preço baixo. Não só estes imigrantes conheciam técnicas agrícolas que os escravos oriundos da África desconheciam, como eram vistos como seres humanos superiores, dentro do escopo das teorias racistas das ciências do século XIX, como a Antropologia, a Frenologia e a Criminologia de Lombroso.

Assim, com o fim da demanda por negros escravizados, as colônias africanas já não são tão atraentes para Portugal; que só com o tempo implanta atividades produtivas nestas terras e comercializa com elas outras coisas que não vidas humanas. Isto se dará no 
final do século XIX. Antes disso, portanto, reinará a desolação de um país que se estruturou nos últimos séculos para acumular riquezas a partir de suas colônias e que agora já não tem colônias rentáveis:

\begin{abstract}
Palmela toda a sua vida dizem ter afirmado que $<<$ Portugal, depois da separação do Brasil, não tinha mais remédio que unir à Espanha〉>. Do lado oposto, vimos Passos confessar na tribuna que o futuro nacional estava na união. A opinião do duque de Palmela firmava-se naturalmente na história do País que vivera por quatro séculos da exploração de territórios ultramarinos e que desde 20 se achava reduzido ao canapé europeu de D. João VI, porque o resto das suas colônias, armazém de escravos apenas, de nada valia desde que o tráfico dos negros era proibido. As finanças nacionais, exprimindo a ruína econômica portuguesa, eram o comentário eloquente da doutrina e a causa imediata mais grave das agitações da política (MARTINS, s/d, 287-288).
\end{abstract}

Voltando ao tema do Brasil, tem-se que, com a independência, o dinheiro brasileiro não deixou de fluir para Portugal, mas agora o faz de modo distinto. Ele não aflui mais como dividendos do Estado, o que revelou ser o maior prejuízo advindo da separação entre os dois países para Portugal, pois aprofundou ainda mais o domínio de particulares endinheirados sobre a coisa pública. $\mathrm{O}$ interesse dos grandes investidores brasileiros era mais um a ser colocado como prioridade, em detrimento dos interesses das classes baixas, e o poder de decidir onde seria investido o capital oriundo da América já não cabia ao Estado, mas aos particulares.

\begin{abstract}
A verdade é que Palmela enganava-se quando supunha o Brasil perdido. O Brasil dá-nos muito dinheiro, sem o trabalho de o governarmos. Mas o que poupamos por esse lado perdemo-lo por outro. Outrora vinham os quintos para o Tesouro, hoje vêm saques para particulares. Esses saques breve se convertem em subscrições é verdade; mas o processo é mau, porque, assim, o Tesouro tem dívidas em vez de rendas; e se por fim, quando o ponto final vier, o resultado tiver sido o mesmo, o ponto trará consigo a mais grave das crises (MARTINS, s/d, vol. II, p.308).
\end{abstract}

Se o Brasil ofuscou as colônias africanas, mesmo depois de independente, a suspensão das remessas de dinheiro dos emigrados e mesmo de investimentos de capitais oriundos deste país, favorecerá o comércio com a África. Será justamente nos anos setenta do século XIX, momento em que ocorre a Guerra do Paraguai, e nos anos oitenta, quando ocorre a abolição da escravatura e a proclamação da república neste país, que o comércio português com as colônias africanas se intensificará e ultrapassará mesmo o comércio com o Brasil. Pouco após o conflito acima mencionado, escreverá Oliveira Martins sobre as desilusões porque passaram os portugueses ao verem seus sonhos de grandeza frustrados: ingressos de dinheiro do Brasil: tudo isso declarou em crise o resto das antigas esperanças 
Outro fator que contribuiu para este acréscimo de investimentos em África é a crise porque o próprio Portugal passa, durante o fim do século. Crise, sobretudo, nas culturas agrícolas destinadas à exportação; que foram afetadas por doenças, pela baixa do preço, pela falta de mão-de-obra devido à emigração e pela concorrência dos Estados Unidos da América. Segundo Alexandre, "A situação das colônias portuguesa em África estava sobretudo dependente da expansão comercial inglesa" (1993, p. 260). Isto porque Portugal não dispunha de pessoal, navios e rotas comerciais para fazer com que suas colônias africanas viessem a ser lucrativas. As colônias que hoje correspondem aos países de Angola, São Tomé e Príncipe, Cabo Verde e Guiné-Bissau tiveram maior relacionamento com a metrópole portuguesa, mas Moçambique, por sua localização geográfica mais distante do dominador lusitano, era mais um território deixado nas mãos dos próprios nativos que uma região de efetivo domínio lusitano. Não que faltasse quem defendesse maior exploração das possessões ultramarinas que ainda restavam a Portugal, após a independência do Brasil, mas este desejo nunca chegou a ser concretizado em plenitude. Fato é, no entanto, que desde o processo de independência de sua colônia americana, a Coroa já escutava vozes que clamavam por uma maior atenção para a África:

É que $<<a$ generalidade da imprensa liberal portuguesa tem, face ao agudizar da crise brasileira, uma de duas atitudes: ou defende posições de força, pretendendo que se obrigue o Brasil (ou pelo menos parte dele) a submeter-se, ou propõe como projecto alternativo o desenvolvimento das possessões africanas>> (ALEXANDRE, 1993, p.659).

Ainda assim, neste momento de crise da economia portuguesa diante da perda do Brasil e de um capitalismo ainda pouco desenvolvido, as colônias em África passam a ser vistas não apenas como importante local de investimento dos capitais excedentes, ainda prenhe de oportunidades por terem sido pouco exploradas economicamente, bem como fascinam pelas expectativas de riquezas imaginárias que geram. A descoberta de diamantes, ouro, prata e pedras preciosas neste continente por parte de outros países europeus colonizadores, sobretudo a Inglaterra, desperta em muitos portugueses a cobiça e a auri sacra fames serve de sustento, para muitos, da ideia de que as colônias africanas poderiam ser a salvação de Portugal.

O escritor português José Maria Eça de Queirós traduziu ou revisou a tradução de um livro que mexia com este imaginário de riquezas sem fim; que lembra a busca do $E l$ Dorado na América. Busca que a tantos europeus matou e que serviu, no entanto, para que os países colonizadores viessem a conhecer melhor as terras que invadiram. O livro em questão é o King Solomon's Mines, de Ridder Haggard, lançado em Portugal em 1891, com o nome de As Minas de Salomão. Nesta obra, expedicionários ingleses partem à procura do irmão de um deles, um homem da nobreza, em terras africanas de difícil acesso. Eles acabam 
por encontrar um tesouro de valor incalculável, do qual trazem apenas uma ínfima parte. $\mathrm{O}$ tesouro está protegido por uma série de armadilhas, o que torna a busca por ele um tanto quanto perigosa, e além de vencerem o clima e as dificuldades do relevo, devem os aventureiros enfrentar uma belicosa, numerosa e bem organizada tribo local. Assim, mesmo após enriquecer consideravelmente o protagonista do romance, a maior parte do tesouro continua acessível a quem conseguir passar pelas duras provas de coragem, vigor e inteligência. $\mathrm{O}$ enredo é quase que um convite para que outros tentem encontrar esta riqueza extraordinária e reflete em parte não apenas aquilo que os ingleses sonhavam encontrar em suas colônias, bem como o sonho de todo colonizador europeu. Isto, sem mencionar o marfim, o comércio de peles de animais selvagens, como leões, e as plantações que poderiam ser realizadas em solo tropical.

As terras africanas, entretanto, ao mesmo tempo que eram vistas como um potencial El Dorado por alguns, também eram encaradas como terras desoladas e inóspitas; local de degredo e infâmia. De fato, muitos, já há muito tempo, vinham sendo condenados por seus crimes ao degredo em África. Isso se deu também com as possessões portuguesas. Assim, nem sempre o elemento colonizador lusitano foi o capitalista organizado e capaz ou o trabalhador capacitado e disciplinado. Durante algum tempo, suas colônias neste continente pareciam mais prisões que locais produtivos e desejáveis. Como não poderia deixar de ser, as colônias africanas refletiam em sua formação social os elementos de sua metrópole.

\footnotetext{
A quarta e última das principais articulações do movimento de consolidação das relações de produção capitalistas em Portugal, da viragem de 1870 até à viragem de 1890, aponta igualmente para um modelo que não incita ao desenvolvimento das forças produtivas: tratase do processo de integração das colónias africanas no espaço económico nacional. Em Oliveira Martins, de longe o maior entendedor do período que vimos analisando, desde o advento do liberalismo mercantil até à crise em que ele próprio interveio como protagonista no decurso da sua breve passagem pelo Governo (1892-93), é clara a percepção do Império Colonial como «válvula de segurança», como lugar de exportação das contradições no seio da classe possidente e da própria formação social (CABRAL, 1976, p.123).
}

Além disso, deve-se atentar para outro ponto: há um elemento que foi essencial para a presença portuguesa em África durante muito tempo e que agora, justamente por causa da política interna da metrópole durante o século XIX, tende a desaparecer: o integrante de alguma ordem religiosa. A proibição da existência de ordens religiosas em Portugal remete à expulsão dos jesuítas pelo Marquês de Pombal e é uma ação liberal de luta contra o Antigo Regime e, portanto, contra o Absolutismo. Esta proibição se deu concomitantemente ao confisco dos bens destas ordens para leilão, a desamortização dos bens de mão-morta. Em África, no entanto, o missionário religioso era fundamental para empreender o tipo de colonização que Portugal sempre empreendera e que se justificava ideologicamente pelo objetivo de levar a religião católica e a salvação das almas a todos os continentes. 
A religião, quando da colonização da América, não era só justificativa perante o resto do mundo, mas sustentáculo da ordem, acalmando os nativos mais exasperados e amalgamando colonizadores e colonizados num mesmo modo de encarar o mundo e a vida, sempre sob a ótica da recompensa após a morte e da submissão aos sofrimentos desta vida. No entanto, sem estes missionários esta vivência, já testada com sucesso no Brasil, fica impedida de funcionar. E se é verdade que a atividade missionária nas colônias portuguesas já não se encontrava em seu auge, mesmo antes da proibição das ordens religiosas em territórios da Coroa, também é verdade que elas ainda vinham ocupando um papel importante na dominação colonial de todo o Império Ultramarino.

\begin{abstract}
Numa memória sobre as ilhas de Solor e Timor, publicada em 1840, atribuía-se este estado de decadência geral à falta de missionários. Ao que parece, quando não tinham padres nas suas terras, os Timorenses conduziam directamente os seus gêneros e víveres às embarcações dos Holandeses, que frequentemente costeavam a ilha, provocando a ruína da alfândega local (ALEXANDRE, 1993, p.251).
\end{abstract}

A colonização agora, portanto, terá de ser distinta; moderna. Não mais missionários e justificativas religiosas, mas funcionários do Estado e a justificativa adotada pelos demais países europeus para disfarçar seus reais interesses: o abnegado desejo de levar ao primitivo a civilização. Acontece, porém, que ninguém perguntou ao dito "primitivo" se ele desejava se tornar "civilizado" e nem mesmo se provou que há mais felicidade em ser "civilizado" na poluída e violenta Manchester que em ser "primitivo" numa bucólica aldeia africana.

Se nas Grandes Navegações, o domínio dos territórios além-mar era justificado ideologicamente pela glória do país e o alargamento das hostes cristãs mediante o gesto de levar a Fé aos gentios, agora a catequização não faz mais sentido, embora a glória estatal ainda seja um argumento aceito. No lugar da Fé, os europeus estariam levando para os outros continentes a Civilização. Dentre os elementos civilizacionais estava a Língua, a Cultura e a Arte europeias (BITTENCOURT, 2014, 82).

Portugal, no entanto, não se preocupa com estes questionamentos de ordem moral, cultural ou filosófica. Quer apenas riquezas e deve apressar-se para rapidamente atender a esta demanda de colonizadores e para a implantação desta nova ótica ideológica, para não perder seus domínios para outras nações europeias. Este país que já teve a experiência de ter sua principal colônia de então (o Brasil) invadida por franceses no século XVI e holandeses no século XVII deveria tomar as devidas precauções para não perder, talvez de modo definitivo, o que restava de seu império colonial. Se os poderosos holandeses e franceses perderam suas colônias na América do Norte para a Inglaterra no século XVIII, por que o mesmo não poderia ocorrer com Portugal, cem anos depois? Parecia mesmo um milagre que isto ainda não tivesse ocorrido.

Não eram apenas os holandeses, porém, que constituíam uma importante concorrência para os portugueses. Até mesmo os brasileiros, por suas antigas e bem estabelecidas relações com a África, lucravam mais com as colônias portuguesas que propriamente Portugal. Isto porque o infame tráfico de seres humanos escravizados acabou por criar relações comerciais entre os continentes 
americano e africano, nomeadamente Brasil e Angola. Sendo que nem os laços portugueses com sua colônia mais importante em África eram tão intensos quanto o envolvimento dela com o Brasil.

\begin{abstract}
A burguesia colonial de Angola era constituída não só pelos agentes directos dos poderosos mercadores residentes no Brasil e por alguns negociantes emigrados de Portugal, como pelas grandes famílias crioulas, bem implantadas e adaptadas ao clima, mantendo ligações estreitas com Portugal e com o Brasil e desenvolvendo, ao mesmo tempo, um bom relacionamento com os Africanos. Chegou a afirmar-se que, nesta altura [meados do século XIX], Angola parecia mais uma colônia brasileira que portuguesa e não foram raras as tentativas no sentido de uma união com o Brasil com vista a garantir a manutenção do tráfico, mas que a Inglaterra sempre conseguiu contrariar (ALEXANDRE, 1993, p.257).
\end{abstract}

Tem-se, pois, um império colonial em crise: os domínios portugueses em terras asiáticas são territorialmente pequenos e não podem representar uma solução para a crise vivida pelo país. Os domínios em África são extensos e importantes, mas pouco explorados. Os custos desta exploração e colonização são altíssimos e o retorno financeiro não é garantido. Aliás, foi este o motivo que fez com que Portugal negligenciasse por tanto tempo suas possessões ultramarinas em continente africano. Negligência que se liga às crises porque passou a própria metrópole e à sua própria configuração social, política e econômica. País de capitalismo pouco desenvolvido, reinam ainda em Portugal as interferências políticas nas transações econômicas; a busca por prestígio, luxo e fama em detrimento do investimento do capital em atividades produtivas e os favorecimentos pessoais.

O pretendente era, na literatura de então, uma personagem quase tão vulgarizada e atacada quanto o agiota; os folhetinistas raramente perdiam uma oportunidade de criticar esse tipo em que, presumivelmente, viam o representante dos seus concorrentes — Latino Coelho [...] definia-o assim:

\begin{abstract}
«O pretendente antes da situação apelida-se vítima [...] espera com atenção o momento de novos ministérios. Até então confunde-se nas tintas, é vítima de injustiças atrozes, está inscrito, diz ele, em todos os livros negros da política, é o alvo constante de todas as perseguições. Umas vezes salvou a pátria e a pátria esqueceu-o. Outra vez são os seus talentos que ele aponta como o escrito de uma dívida sagrada que o país contraiu com ele. Outras vezes são as suas virtudes, a sua inteireza, a austeridade incorruptível do seu carácter, que lhe dão o direito de ser chamado aos mais eminentes postos da república [...]. Pede, implora, suplica, arrasta-se, lambe; e de repente manda, sentencia, ira-se, apruma-se, condena e excomunga. Ninguém é mais flexível enquanto dura a esperança, ninguém mais Catão depois da recusa formal; Francisco Maria Bordalo comentava: «É desgraça que se não imprima diversa direcção às tendências da mocidade, que se não afaste a juventude da horrível tentação de girar em tomo das secretarias de estado, procurando enroscar-se como bicho-da-seda nas folhas do orçamento! E a agricultura, e a indústria, e o comércio, $e$ as nossas ricas possessões ultramarinas, que oferecem tão vasto campo à inteligência e ao trabalho — tudo abandonado ou entregue a mãos inábeis!...> (SANTOS, 1979, p.100, grifo meu.)
\end{abstract}

Assim, as possessões coloniais são vistas como ricas, porém mal aproveitadas; dirigidas por pessoas incompetentes, o que privaria o país de recursos necessários para seu progresso e desenvolvimento. Há que se lembrar que as colônias portuguesas em África faziam fronteira com as colônias britânicas. A Inglaterra tem uma política colonial agressiva e presente, desenvolvendo 
sempre um relacionamento intenso com suas possessões imperiais. Os ingleses, sim, são vistos como bons administradores de suas colônias e capazes de delas retirar lucros. Além disso, a segurança das colônias portuguesas e mesmo o transporte regular de mercadorias e pessoas dependia, em parte, de ações inglesas de contenção de revoltas de tribos hostis. Por conseguinte, alguns chegaram mesmo a propor que se vendesse aos ingleses algumas destas possessões que Portugal mostrava-se incapaz de aproveitar. Estes, certamente, demonstravam grande interesse em aumentar suas possessões africanas, como demonstra o ultimatum e os conflitos em torno de Lourenço Marques (atual Maputo; capital de Moçambique).

Desta dificuldade de exploração e da tentativa de garantir para si uma porção considerável e estrategicamente localizada do território africano é que surge o projeto português do "mapa corde-rosa", que daria a Portugal uma extensa faixa de terra, ligando o litoral atlântico ao índico e Moçambique à Angola. Certamente, a posse deste enorme território traria consideráveis vantagens geopolíticas ao pequeno país europeu e possibilitaria criar uma rota de comércio lucrativa, utilizando para isso os rios da região.

Os ingleses, porém, têm o mesmo desejo e o conflito de interesses é já antigo e notório. O Ultimato Britânico, em 1890, vem garantir a concretização dos planos ingleses, a despeito da presença histórica de Portugal na região. O país todo sente-se humilhado e a comoção diante da fraqueza da nação é misturada ao ódio xenófobo ao inglês, levando alguns portugueses mais exaltados mesmo a agressões físicas e outros crimes contra cidadãos britânicos.

Em 1886, eram assim reclamadas as regiões entre Angola e Moçambique no célebre «mapa cor-de-rosa», projecto que desde muito se sabia colidir com o de Cecil Rhodes. Como resposta, o Governo britânico apresentava a Portugal, em 11 de janeiro de 1890, por intermédio do seu ministro em Lisboa, um ultimato formal, exigindo a imediata retirada das forças militares das áreas que considerava fora da soberania portuguesa em Moçambique, isto é o abandono da zona do Chire e das terras dos Macalolos e Machonas.

Não será difícil avaliar o choque profundo e duradouro que o Ultimato britânico provocou em Portugal. Na verdade, a cedência passiva da corte à pressão exercida pela «velha aliada» viria a provocar um descontentamento profundo e a acentuar uma não menos profunda divisão na sociedade portuguesa. Em torno da ideia de império se iriam cristalizar os sentimentos nacionalistas, tecendo-se mitos à volta dos territórios ultramarinos, então encarados como «parcelas sagradas» de um patrimônio a cujos direitos se tentava associar a «vocação ultramarina portuguesa». Nesta ambiência de «euforia colonial», as ocupações militares eram encaradas como único meio capaz de fazer afirmar a posse dos domínios ainda restantes. Parece poder concordar-se com Jaime Cortesão, quando afirmava que « no fundo das nossas mais fortes comoções internas aparecem a determiná-las os interesses ultramarinos» (ALEXANDRE, 1993, p.266).

Não se pode esquecer, porém, que, se o Ultimato Britânico mobiliza os portugueses à defesa de seu território colonial e fortalece aqueles que defendem a intensa exploração das colônias como saída para a crise da metrópole, nem sempre a atividade colonial encontrou tantos defensores. Durante todo o século XIX, aliás, muitos se opuseram a ela, afirmando-a custosa, arriscada e pouco rentável. Em oposição, defendiam o melhor aproveitamento do próprio território português.

Este debate foi ficcionalizado por Eça de Queirós, n'A Ilustre Casa de Ramires, mas ele não existe apenas na ficção, perpassando todo o século XIX português. De fato, Oliveira Martins já 
apresenta o embate entre Mouzinho e Palmela em torno deste tema. A principal justificativa dos que condenam a colonização africana é que o maior aproveitamento de terras portuguesas ainda pouco povoadas e pouco exploradas economicamente poderia render mais lucros, seria mais fácil e menos arriscado. Os riscos que a África traz não são apenas os de morte: doenças, conflitos armados, naufrágios, feras... existem também os riscos econômicos. Como os custos são altos, o empreendimento é bastante arrojado e ousado.

Os defensores da maior exploração do solo pátrio chegam a propor que o uso dinheiro advindo da venda dos territórios coloniais a outros países europeus acabaria por ajudar Portugal a desenvolver-se mais e isso seria melhor que manter as colônias abandonadas aos próprios africanos; como de fato estavam, em muitos casos. Maria Manuel Lisboa relata a posição de Oliveira Martins a respeito das possessões ultramarinas lusitanas em África:

\begin{abstract}
Segundo Oliveria Martins, a identidade (e vitalidade) de Portugal enquanto nação independente destacada da Espanha só se manteve graças ao impulso atlântico. A ambivalência do autor da História de Portugal relativamente ao sonho imperial e ao projecto do mapa cor-de-rosa em África, porém, levou-o, embora com reservas, a declarar a função das colónias (produto desse atlantismo) como, na melhor das hipóteses, a muleta efémera que prolongaria apenas temporariamente os benefícios de uma jurisdição colonial insustentável a longo prazo por uma nação pequena (LISBOA, 2000, p.19-20).
\end{abstract}

Na obra de Eça, o Alentejo é defendido por Gouveia, funcionário público da pequena localidade de Vila-Clara, enquanto terra merecedora de maior atenção ("Província abandonada, sim! Abandonada miseravelmente, desde séculos, pela imbecilidade dos governos... Mas riquíssima, fertilíssima!” (QUEIRÓS, 1999, p. 105). Enquanto Titó e Gonçalo, nobres da mesma localidade, defendem a exploração das colônias africanas. A discussão fica acirrada, sem nenhum consenso e, no fim da obra, Gonçalo acaba ele próprio por emigrar para a África, conseguindo lá algum sucesso. À espera do colonizador, que volta agora para Portugal, Titó, Gouveia e Videirinha (outro amigo de Gonçalo) se dirigem à Torre, para saber notícias de sua chegada. Vendo os melhoramentos nela feitos, Titó provoca Gouveia, que duvidava da rentabilidade da exploração africana: "Veja você! exclamou ele para o Gouveia, que acendia o charuto. — Você a negar!... Mobílias, obras, égua inglesa... Tudo já dinheiro de África" (QUEIRÓS, 1999, p. 453).

No entanto, não se pode esquecer que, de fato, como afirmam Neto e Vaquinhas, a realidade não deixou de dar razão também a Gouveia, uma vez que se vê, ainda no século XIX, o “Alentejo, convertido no «celeiro de Portugal»" (Neto; Vaquinhas, 1998, p.286). Quem estava certo: os defensores da intensificação da colonização da África ou os advogados do maior aproveitamento do próprio território português? Talvez os dois grupos.

Com efeito, o Alentejo chegou mesmo a destacar-se das demais regiões do país por suas relações produtivas mais modernas e capitalistas. Talvez, até mesmo pelo seu estado de relativo abandono tenha sido mais fácil implantar ali um modelo que não se consolidou sem gerar resistências em todos os locais em que foi adotado. 
Só para dar um exemplo: enquanto a França resolvera o problema da «liberdade da terra» em 1789, os últimos vínculos portugueses sobreviveriam até 1863 e os baldios, compáscuos, campos abertos, etc, só pelo Código Civil de 1867 seriam colocados em regime legal de plena propriedade (e só no Alentejo se pode considerar terem sido praticamente destruídos por volta de 1875, já no âmbito de nova etapa do desenvolvimento do MPC em Portugal). Dito isto, tem razão Oliveira Martins quando diz ser a Regeneração o «nome português do capitalismo» Com a viragem do século, tem o seu desfecho a batalha entre os dois modos de produção. A dominação do MPC não implica, porém, o desaparecimento imediato e total das relações de produção pré-capitalistas, nem seria de grande utilidade dizer que é a sua resistência que trava o desenvolvimento das forças produtivas. O que importa, sim, é caracterizar $o$ modo como se articulam relações de produção que relevam de modos de produção diferentes e como o MPC submete a si, e em que medida, os sectores précapitalistas (CABRAL, 1976, p.115).

\section{Considerações finais:}

Percebe-se, portanto, que a questão do domínio português na África não é tão simples como pode parecer à primeira vista. Não se tratava de consciência ou falta de consciência - da Coroa ou do gabinete que estivesse no poder - da importância das colônias africanas. Tampouco, tratavase de uma questão consensual em todo o país. Explorar ou não com mais intensidade as possessões ultramarinas lusitanas significavam, uma vez que os recursos do país eram extremamente escassos, era uma decisão que deveria ser tomada com cuidado. Afinal, implicava em ter de escolher entre aproveitar melhor seu próprio território ou negligenciá-lo.

Significava também encontrar novas formas de exploração, já que a antiga colonização pautada na aliança com a Igreja Católica e dependente da atuação de seus missionários, já não se fazia possível. Ao menos, não se a consolidação do Liberalismo fosse vista como uma prioridade da qual não se poderia abrir mão.

Há que se pensar, ainda, que a consolidação do domínio ultramarino africano passava pela iminência do enfrentamento de outras potencias colonizadoras, sobretudo a Inglaterra. Valeria a pena enfrentar inimigos tão poderosos? Teria Portugal, de fato, condições de garantir seus domínios diante da presença em parte de suas colônias de mercadores e tropas inglesas? Diante do fato de que a Inglaterra não apenas era a maior potência do mundo naquele momento, mas também dispunha da maior e mais poderosa marinha (algo fundamental para o acesso às colônias, sobretudo Moçambique), investir nas possessões ultramarinas poderia resultar em dinheiro jogado fora. Afinal, de que valeria realizar investimentos de longo prazo (sem os quais as colônias permaneceriam impossíveis de serem exploradas comercialmente) se não havia garantia de que Portugal um dia colheria os frutos destes sacrifícios?

Por fim, a própria experiência de Portugal com o Brasil independente influenciava alguns cidadãos a defenderem relações mais frouxas e um domínio mais moral que efetivamente militar. Afinal, a se dar crédito a Oliveira Martins, a antiga colônia não deixou de dar lucros à metrópole, ainda que estes dividendos viessem agora em prol de particulares e não mais em prol da Coroa. Em todo caso, o Brasil servia de exemplo para aqueles que defendessem uma tentativa de ter para com as possessões africanas uma relação mais de trocas comerciais que de efetivo domínio colonizador.

Deve-se sempre ter em mente que Portugal, na segunda metade do século XIX, estava 
longe de ser uma potência. Seus recursos eram escassos, sua população pouco instruída, seu poderio militar extremamente vulnerável, sua estabilidade política apenas a duras penas conseguida. Foi este país que conseguiu manter grande parte de suas possessões ultramarinas até os anos setenta do século XX. Talvez não tenha retirado delas tantas riquezas como alguns defensores da colonização defendiam, mas o fato é que as condições que Portugal dispunha também não eram as melhores. Além disso, seriam suas colônias tão ricas como alguns diziam? Fato é que não estavam entre as que mais possuíam jazidas minerais ou outras riquezas especialmente importantes para a Europa da época, como a África do Sul, por exemplo.

\section{Referências:}

ALEXANDRE, V. Os sentidos do Império: Questão Nacional e Questão Colonial na crise do Antigo Regime Português. Porto, Afrontamento, 1993

BITTENCOURT, R. P. "Teófilo Braga: a História Literária como Testemunha da Glória de Portugal". In: Revista Magistro, vol. 9, núm. 1, 2014, p. 66-88.

CABRAL, M. V. "Sobre o século XIX português: a transição para o capitalismo". In: Análise Social, vol. XII (45), $1^{\circ}$ num., 1976, p.106-126.

LISBOA, M. M. Teu amor fez de mim um lago triste - ensaios sobre «Os Maias». $1^{\text {a }}$ Edição, Porto, Campo das Letras, 2000.

MARTINS, J. P. O. Portugal Contemporâneo. 2 vols. Mira-Sintra, Europa-América, s/d.

NETO, M.; VAQUINHAS, I. M. “Agricultura e Mundo Rural: tradicionalismo e inovações”. In: TORGAL, L. R.; ROQUE, J. L. (org.) História de Portugal: o Liberalismo. Direção de José Mattoso. Lisboa, Editorial Estampa, 1998, p. 279-289.

QUEIRÓS, J. M. R. A Ilustre Casa de Ramires. Edição Crítica das obras de Eça de Queirós. Direção de Carlos Reis. Lisboa, Imprensa nacional - Casa da Moeda, 1999.

SANTOS, M. L. L. "Sobre os intelectuais portugueses no século XIX (do Vintismo à Regeneração)" In: Análise Social, vol. XV (57), $1^{\circ}$ núm., 1979, p.69-115.

Recebido: 01/04/2021

Aceito: 20/08/2021

Publicado: 18/02/2022

\footnotetext{
' Doutor em Literatura de Língua Portuguesa: Investigação e Ensino (Universidade de Coimbra, 2017). http://lattes.cnpq.br/7719768662629907 Orcid iD https://orcid.org/0000-0003-0099-5098
} 